\title{
INTERSTITIAL PNEUMONITIS AFTER ACETYLENE WELDING: A CASE REPORT
}

\author{
MIRAN BRVAR \\ University Medical Centre Ljubljana, Ljubljana, Slovenia \\ Poison Control Centre, Division of Internal Medicine
}

\begin{abstract}
Acetylene is a colorless gas commonly used for welding. It acts mainly as a simple asphyxiant. In this paper, however, we present a patient who developed a severe interstitial pneumonitis after acetylene exposure during aluminum welding. A 44-year old man was welding with acetylene, argon and aluminum electrode sticks in a non-ventilated aluminum tank for $2 \mathrm{~h}$. Four hours after welding dyspnea appeared and $22 \mathrm{~h}$ later he was admitted at the Emergency Department due to severe respiratory insufficiency with $\mathrm{pO}_{2}=6.7 \mathrm{kPa}$. Chest X-ray showed diffuse interstitial infiltration. Pulmonary function and gas diffusion tests revealed a severe restriction (55\% of predictive volume) and impaired diffusion capacity (47\% of predicted capacity). Toxic interstitial pneumonitis was diagnosed and high-dose systemic corticosteroid methylprednisolone and inhalatory corticosteroid fluticasone therapy was started. Computed Tomography (CT) of the lungs showed a diffuse patchy ground-glass opacity with no signs of small airway disease associated with interstitial pneumonitis. Corticosteroid therapy was continued for the next 8 weeks gradually reducing the doses. The patient's follow-up did not show any deterioration of respiratory function. In conclusion, acetylene welding might result in severe toxic interstitial pneumonitis that improves after an early systemic and inhalatory corticosteroid therapy.
\end{abstract}

Key words:

Acetylene, Welding, Pneumonitis, Corticosteroides

\section{INTRODUCTION}

Acetylene (HCCH, CAS 74-86-2) is a colorless inflammable gas commonly found in an industrial agent that, when mixed with oxygen, is used for welding [1]. Inhalation of acetylene is a major route of exposure and poisoning, but there are no data available on the kinetics and metabolism of acetylene in humans or animals [2]. It acts as a simple asphyxiant by diluting oxygen in the air and as a narcotic causing anesthesia, but it is non-irritant to the skin and mucus membranes [1,2]. The symptoms of acetylene inhalation include dizziness, headache, fatigue, nausea, vomiting, tachycardia and tachypnea [2]. Exposure to a high concentration of acetylene may result in a loss of consciousness and death [1].
In this paper we are presenting a patient who developed a severe interstitial pneumonitis after acetylene welding.

\section{CASE REPORT}

A 44-year old man with no previous medical history was welding for $2 \mathrm{~h}$ with acetylene, argon and aluminum electrode sticks ( $\mathrm{AlSi}_{5}$ ) containing $95.110 \%$ of aluminium, $4.590 \%$ of silicon, $0.260 \%$ of iron, $0.018 \%$ of titanium, $0.008 \%$ of manganese, $0.007 \%$ of magnesium, $0.006 \%$ of copper and $0.001 \%$ of zinc in a non-ventilated aluminum tank with a capacity of $7 \mathrm{~m}^{3}$. Before welding, the tank was utterly cleaned from oil that was previously in

Received: October 13, 2013. Accepted: December 16, 2013.

Corresponding author: M. Brvar, University Medical Centre Ljubljana, Division of Internal Medicine, Poison Control Centre, Zaloška cesta 7, 1000 Ljubljana, Slovenia (e-mail: miran.brvar@kclj.si). 
the tank. Immediately after welding the study subject felt dizzy and weak. The dizziness disappeared in the 1st hour of breathing fresh air, but $4 \mathrm{~h}$ after welding the subject started feeling worse again, this time with a progressive shortness of breath.

$22 \mathrm{~h}$ after welding the subject arrived at the Emergency Department reporting severe dyspnea. The vital symptoms included: tympanic temperature of $36.3^{\circ} \mathrm{C}$, pulse 80 beats/min, blood pressure supine 130/75 mm Hg, respiratory rate 24 counts/min and $\mathrm{SpO}_{2} 86 \%$ on room air. The subject's breathing was shallow and on auscultation inspiratory bilateral basal crackles were found. The remaining physical examination was otherwise unremarkable and no neurological signs were detected. Initial laboratory test results showed leucocytosis $\left(15.2 \times 10^{9} / 1\right)$. Serum glucose, electrolytes, BUN, creatinine, hepatocellular enzymes, creatine kinase, myoglobine and troponine I were normal. Arterial blood gas analysis revealed respiratory insufficiency with $\mathrm{pH}=7.40, \mathrm{pCO}_{2}=4.8 \mathrm{kPa}, \mathrm{pO}_{2}=6.7 \mathrm{kPa}$ and bicarbonate $=21.8$ mmoll while breathing ambient air (Figure 1).

The serum aluminum level was $0.15 \mu \mathrm{mol} / \mathrm{l}$ (normal limits $<0.37 \mu \mathrm{mol} / \mathrm{l})$. An ECG revealed a normal sinus rhythm and the chest X-ray showed diffuse interstitial infiltration. Pulmonary function and gas diffusion tests revealed a severe restriction and impaired diffusion capacity with the forced vital capacity 2.751 (57\% of predicted capacity), forced expiratory volume 2.041 (54\% of predicted volume) and carbon monoxide diffusing capacity 4.7 (47\%

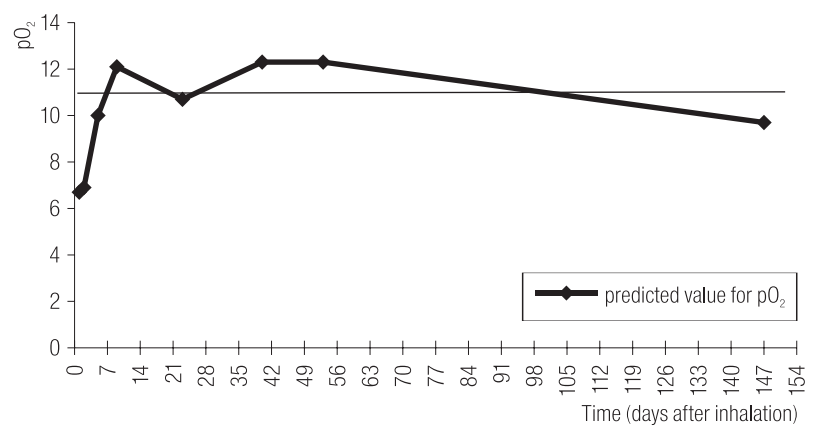

Fig. 1. Partial oxygen pressure $\left(\mathrm{pO}_{2}\right)$ in the patient after acetylene welding

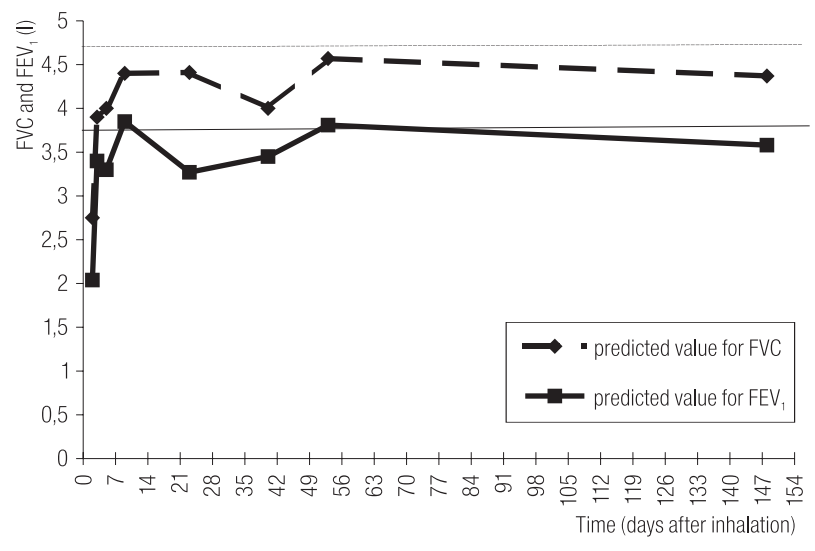

Fig. 2. Forced vital capacity (FVC) and forced expiratory volume $\left(\mathrm{FEV}_{1}\right)$ in the patient after acetylene welding

of predicted capacity) (Figures 2 and 3). Toxic interstitial pneumonitis associated with acetylene and metals inhalation in a non-ventilated area was diagnosed and systemic corticosteroid methylprednisolone $(1 \mathrm{mg} / \mathrm{kg} / \mathrm{day})$ and inhalatory corticosteroid fluticasone $(0.5 \mathrm{mg} / 12 \mathrm{~h})$ therapy was applied on the 2nd day.

The patient was also treated with $40 \%$ oxygen, inhalation of beta-agonists salbutamol and salmeterol as well as with moxifloxacin antibiotic as infection could not have been completely ruled out. On the 3rd day after welding the high resolution CT axial imaging of the lungs showed diffuse patchy ground-glass opacity without any signs of small airway disease associated with interstitial pneumonitis (Photo 1).

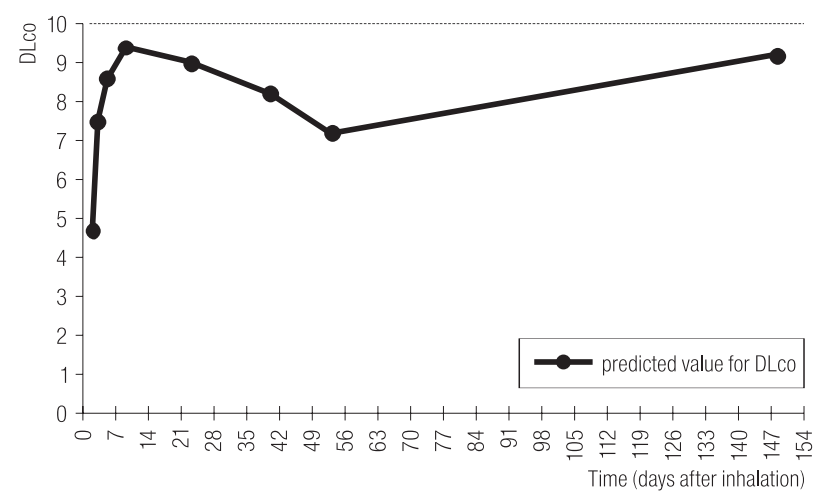

Fig. 3. Carbon monoxide diffusing capacity (DLco) in the patient after acetylene welding 


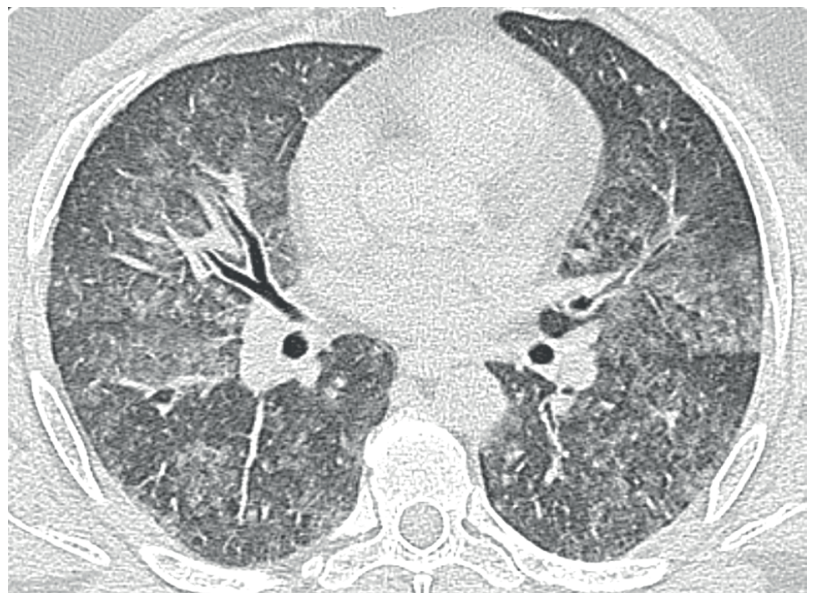

Photo 1. High resolution CT axial imaging of the lungs on the 3rd day after acetylene welding

A subsequent clinical course and negative cultures of sputum and blood as well as serologic tests regarding respiratory viruses and atypical bacteria ruled out an infection. Rheumatic pulmonary disease was also excluded. The patient's symptoms, arterial oxygenation, pulmonary function and gas diffusion tests rapidly improved during the 1st week of the treatment and almost reached expected values on the 9th day after welding (Figures 1-3). The chest X-ray completely normalized. The patient was discharged on the 9th day after inhalation, but corticosteroid therapy was continued for the next 8 weeks with gradually reduced doses.

The patient's follow-up, during 8 weeks, of corticosteroid therapy, 5 months afterwards revealed the 2nd transient deterioration in respiratory function between the $2 \mathrm{nd}$ and 7 th week after welding which completely normalized until 5 months later (Figures 1-3). Five months after welding the high resolution $\mathrm{CT}$ axial imaging of the lungs was completely normal. After 2 years the patient's pulmonary function, gas diffusion tests and $\mathrm{CT}$ axial imaging of the lungs were normal.

\section{DISCUSSION}

In this patient transient dizziness and weakness after welding with acetylene were not unexpected since acetylene acts as a simple asphyxiant and a narcotic [1]. Signs of metal fume fever (fever, nausea, headache, myalgias and arthralgias) did not appear, despite the fact that the patient was exposed to at least minimal concentrations of the metals such as zinc, copper, manganese, magnesium and titanium. What is interesting about this patient, is the fact that the delayed interstitial pneumonitis with a severe respiratory distress occurred only several hours after welding which could have been a result of acetylene exposure, since the patient had no other signs of the above mentioned metals toxicity, particularly metal fume fever. It is estimated that about $1500 \mathrm{l}$ of acetylene was used in the tank with a capacity of $7 \mathrm{~m}^{3}$ during $2 \mathrm{~h}$ of welding, however, it is very difficult to estimate the acetylene concentration. Nevertheless, it had to be below the lower explosive limit of acetylene $(2.5 \%)$ since there was no explosion during welding [2].

Interstitial pneumonitis after acetylene inhalation during welding has not been reported yet, but pure acetylene inhalation in a suicide attempt resulted in an acute eosinophilic pneumonia [3]. In the case of this particular patient, lung histological analysis was not performed, but there were no peripheral eosinophilia or other signs of eosinophilic pneumonia. However, inhalation of acetylene with metal fumes, such as zinc, released during welding, could lead to interstitial lung infiltration and an acute respiratory distress syndrome [4]. But in this case interstitial pneumonitis due to zinc inhalation was not very probable, since aluminum electrode sticks $\left(\mathrm{AlSi}_{5}\right)$ contain only minimal quantity of zinc $(0.001 \%)$ and the estimated amount of zinc released in the non-ventilated tank during welding was only $2.3 \mathrm{mg}$ and maximum zinc fumes (including the most common toxic zinc oxide fume) air level $0.33 \mathrm{mg} / \mathrm{m}^{3}$ which is significantly below permissible zinc oxide shortterm exposure limit $\left(10 \mathrm{mg} / \mathrm{m}^{3}\right)$ as well as below zinc oxide air level recorded in the published case of an acute respiratory distress syndrome after metal fumes exposure [4]. Besides, the patient had no other signs of zinc toxicity, such as metal fume fever [5]. Other metals present in the aluminum stick used by this patient, such as copper, 
manganese, magnesium and titanium could also cause metal fume fever, but there is insufficient evidence to conclude that exposures to dusts and fumes of the above mentioned metals could induce acute pneumonitis [6-10]. Furthermore, in the case of this subject aluminum, iron and silicon released during welding with an aluminum stick are not known to cause an acute respiratory distress syndrome nor metal fume fever.

The patient with interstitial pneumonitis but without any signs of a small airway disease was treated by corticosteroids since interstitial pneumonitis of different etiology can result in pulmonary fibrosis. Corticosteroid therapy in interstitial pneumonitis after inhalation injury has not been proven yet, but corticosteroid therapy is probably helpful in the patients who are likely to develop bronchiolitis obliterans or bronchiectasis at a later day after inhalation injury. While going through toxicological books and Medline database, we have found only one report of corticosteroid therapy in acetylene exposure and the data regarding the type, dose and duration of corticosteroid therapy in such patients were missing [11].

The patient described in this paper was treated with a high dose of systemic corticosteroid methylprednisolone and inhalatory corticosteroid fluticasone. During the 1st week of the corticosteroid therapy the patient's condition improved significantly. Afterwards, for the next 8 weeks the patient was treated with progressively reduced doses of systemic methylprednisolone and inhalatory fluticasone in order to prevent inflammatory reactivation and pulmonary fibrosis, since between the 2nd and 7 th week after welding transient deterioration of respiratory function occurred, particularly regarding carbon monoxide diffusing capacity which confirms interstitial pneumonitis and excludes isolated non-cardiogenic pulmonary edema after acetylene exposure. Ultimately, the patient remained asymptomatic with normal arterial oxygen pressure and pulmonary morphology and function tests.
It is difficult to draw any conclusions based on only one case report, but the treatment applied in this patient, i.e. systemic and inhalatory corticosteroid therapy, seems reasonable and effective in toxic exposure during acetylene welding. Possibly the treatment with a high dose of corticosteroids should be prolonged beyond one week, due to the transient deterioration of respiratory function after the 1st week when the patient was treated with progressively reduced doses of corticosteroids. However, further studies are required as clinical improvement in the case of toxic exposure during acetylene welding might be also spontaneous.

\section{CONCLUSION}

Acetylene welding might result in severe interstitial pneumonitis that improves after an early systemic and inhalatory corticosteroid therapy.

\section{REFERENCES}

1. Williams NR, Whittington RM. Death due to inhalation of industrial acetylene. J Toxicol Clin Toxicol. 2001;39(1):69-71, http://dx.doi.org/10.1081/CLT-100102882.

2. Foxall K. Acetylene: Toxicological overview. Toxicology department of Public Health England. [Online] 2009 [cited 2013 Oct 10]. Available from: http://www.hpa.org.uk/web/ HPAwebFile/HPAweb_C/1246260034508.

3. Takamizawa A, Amari T, Kubo K. A case of acute eosinophilic pneumonia induced by inhalation of acetylene. Nihon Kokyuki Gakkai Zasshi. 2000;38(12):947-51.

4. Barbee JY Jr, Prince TS. Acute respiratory distress syndrome in a welder exposed to metal fumes. South Med J. 1999; 92(5):510-2, http://dx.doi.org/10.1097/00007611-19990500000012.

5. Tojima H, Ando T, Kishikawa H, Tokudome T. A welder with chemical pneumonitis caused by inhalation of zinc fume. Nihon Kokyuki Gakkai Zasshi. 1998;36(4):394-8. 
6. Barceloux DG. Manganese. J Toxicol Clin Toxicol. 1999;37(2): 293-307, http://dx.doi.org/10.1081/CLT-100102427.

7. Roels H, Lauwerys R, Buchet JP, Genet P, Sarhan MJ, Hanotiau I, et al. Epidemiological survey among workers exposed to manganese: effects on lung, central nervous system, and some biological indices. Am J Ind Med. 1987;11(3):307-27, http://dx.doi.org/10.1002/ajim.4700110308.

8. Hartmann AL, Hartmann W, Bühlmann AA. Magnesium oxide as cause of metal fume fever. Schweiz Med Wochenschr. 1983;113(21):766-70.
9. Otani N, Ishimatsu S, Mochizuki T. Acute group poisoning by titanium dioxide: inhalation exposure may cause metal fume fever. Am J Emerg Med. 2008;26(5):608-61, http:// dx.doi.org/10.1016/j.ajem.2007.08.018.

10. Borak J, Cohen H, Hethmon TA. Copper exposure and metal fume fever: lack of evidence for a causal relationship. AIHAJ. 2000;61(6):832-6.

11. Bydash J, Kasmani R, Naraharisetty K. Metal fume-induced diffuse alveolar damage. J Thorac Imaging. 2010;25(2): W27-9, http://dx.doi.org/10.1097/RTI.0b013e31819f937f.

This work is available in Open Access model and licensed under a Creative Commons Attribution-NonCommercial 3.0 Poland License - http://creativecommons.org/ licenses/by-nc/3.0/pl/deed.en. 